\title{
Leitthema
}

Bundesgesundheitsbl 2013 · 56:67-75

DOI 10.1007/s00103-012-1582-4

Published online: 19. Dezember 2012

c) Springer-Verlag Berlin Heidelberg 2012

M.A.B. van der Sande ${ }^{1,2}$ - A. Jacobi ${ }^{1}$ A. Meijer ${ }^{1}$ J. Wallinga ${ }^{1}$ W. van der Hoek ${ }^{1}$. M. van der Lubben ${ }^{1}$

${ }^{1}$ RIVM - Centre Infectious Disease Control, National Institute for

Public Health and the Environment, Bilthoven

2 Julius Center for Health Sciences and Primary Care, University Medical Center Utrecht

\section{The 2009 influenza A (H1N1) pandemic}

\section{Management and vaccination strategies in The Netherlands}

er public health regions. To optimize collaboration, each of the seven regions has identified a public health doctor and a regional microbiologist as a liaison with the $\mathrm{CIb}$; these 14 regional professionals have a part-time appointment at the $\mathrm{CIb}$. The CIb also has the task of setting up an outbreak management team (OMT), consisting of fixed members and additional experts invited personally, in the case of a novel or unexpected outbreak of infectious diseases that may spread nationwide. To prepare for a potential outbreak and to support daily control activities, a response team can be formed immediately at the $\mathrm{CIb}$ after the first signs of an outbreak. The Health Council of The Netherlands is an independent scientific advisory body that provides the government and parliament with advice on issues concerning public health, including vaccination strategies.

To guide pandemic preparations, static and dynamic mathematical transmission scenario studies had been conducted to estimate the potential impact on society and on the healthcare sector under various assumptions of a new human influenza pandemic $[1,2]$.

Then, in 2003, The Netherlands was unexpectedly confronted by a large outbreak of influenza A/H7N7 among poultry. Outbreak investigations were initiated, diagnostics were developed, and extensive control measures were implement- ed to stop transmission. This resulted in the culling of 30 million birds, 89 human infections were confirmed, and one casualty occurred [3].

This experience-as well as the threat of the SARS coronavirus in 2003, an ongoing threat of influenza $\mathrm{A}(\mathrm{H} 5 \mathrm{N1})$, and the need to implement the new International Health Regulations-resulted in the development of multidisciplinary protocols for surveillance, diagnostics, communication, control, and research aimed at the various phases of a potential influenza pandemic. All were developed in close collaboration with regional laboratories and health services, and with the veterinary sector (since an avian introduction was considered highly likely) [4].

Thus, when the 2009 pandemic outbreak occurred, The Netherlands, with its 16.5 million inhabitants, should have been well prepared to monitor and control the outbreak. Here, we discuss several aspects of the actual management, with specific attention to vaccination strategies, and reflect on the lessons learned.

\section{Preparations}

A large number of organizations were involved in the pandemic preparations. These preparations included development of multisectoral guidelines, strengthening of surveillance, strengthening of diagnostic surge capacity, preparing commu- 
nication tools, preparing research protocols, stockpiling of antivirals, and arrangements for advance purchase of pandemic vaccinations and for the distribution logistics.

\section{Guidelines}

Three separate multidisciplinary evidence-based response guidelines had been developed coordinated by the CIb for the public health sector: one dealing with incidental introduction (with a focus on avian influenza, in view of the $2003 \mathrm{ex}$ perience), another with a focus on dealing with early introduction of a potentially pandemic virus, and a third one to guide public health management during pandemic transmission. In these guidelines, detailed operational information for professionals on how to manage cases and to control transmission was given, and reference was made to the need for surveillance, diagnostic capacity, correct use of antivirals, and prioritizing of vaccinations.

Furthermore, the professional organizations of general practitioners (GPs) [5], nursing home physicians, and occupational health physicians had prepared their own guidelines in line with the public health guidelines. On a regional lev$\mathrm{el}$, the safety regions developed pandemic plans in cooperation with the PHSs. In all regions these plans were audited by the Dutch Health Inspectorate using a fixed set of indicators. The Ministry of Health in liaison with the Ministry of Interior Affairs prepared intersectoral contingency planning, and private companies drafted their own contingency plans. The ministry together with the $\mathrm{CIb}$ prepared communication leaflets for the general public and an extensive set of Q\&As, to be finalized and updated should a pandemic emerge.

\section{Surveillance}

Routine surveillance of influenza was already strong in The Netherlands, with a sentinel GP network coordinated by NIVEL (Netherlands Institute for Health Services Research) covering around $1 \%$ of the population dating back to 1970 providing influenza-like illness (ILI) trends by age, sex, and region [6, 7]. Since the 1992/1993 influenza season, in a subsample of ILI patients, centralized virology testing has been performed at the RIVM/CIb with additional data on vaccination and selected comorbidity available. To strengthen this, efforts were made to increase the number of participating GPs, to increase the amount of sampling, and to develop a more systematic approach to sampling and data collection. To enable surveillance of more severe outcomes, GPs monitoring ILI were also asked to monitor pneumonia. Furthermore, a sentinel nursing home network was started in 2006, which included influenza/ILI and pneumonia surveillance, similar to the GP sentinel surveillance [8].

Influenza virus surveillance is also routinely undertaken by the Erasmus Medical Centre at Rotterdam University, where influenza virus isolates are typed and analyzed from hospitalized patients as well as ILI patients presenting to sentinel outpatient services, providing input for WHO vaccine selection. Erasmus Medical Center together with RIVM/CIb forms the Dutch National Influenza Centre (NIC), which collaborates with NIVEL for the GP sentinel surveillance. Together they ensure continuous online weekly updates of the influenza situation and weekly newsletters are provided during influenza epidemics. At Erasmus Medical Center, viruses from the sentinel surveillance and from selected hospitalized patients are subtyped on a routine basis. In the preparation for a potential emergence of antiviral resistant virus variants, if (stockpiled) antivirals would be widely used, the NIC developed assays to detect such variants $[9,10]$. Using these assays, the NIC and other dedicated laboratories were able to characterize the emergence of oseltamivir-resistant $\mathrm{A}(\mathrm{H} 1 \mathrm{~N} 1)$ influenza viruses during the 2007/2008 season and during the pandemic $[11,12]$. Finally, as part of a routine pathogen surveillance program, a number of medical microbiology laboratories throughout the country report the weekly number of positive laboratory results for influenza virus and other respiratory viruses.

\section{International collaboration}

Staff of the RIVM/CIb actively participated in several meetings that were organized by ECDC in the years before the 2009 pandemic. This included discussions on a range of options for "surveillance in a pandemic." While some countries favored alternative surveillance instruments, for example, based on telephone consultations, The Netherlands decided to rely on the existing GP and nursing home sentinel surveillance systems.

\section{Laboratory capacity}

During a pandemic, testing requests could be expected to increase sharply, both owing to the large number of expected influenza patients and the increased need to exclude influenza among people who could be infected [4]. To ensure sufficient laboratory capacity would be available, the RIVM with local laboratories developed a method to ensure rapid scaling up, using standardized protocols [13].

\section{Research}

A generic research proposal to study transmission risks following the introduction of a new influenza virus was prepared and received ethical approval in 2006. This facilitated combined epidemiological, clinical, veterinarian, virological, immunological, and perception research among cases and controls during the 2009 pandemic $[12,14,15,16]$. The proposal included a"first few hundreds" approach, and enabled the conduct of a serosurvey among a random subsample of the population before and after the pandemic [17].

\section{Antivirals and vaccines}

Analysis of previous pandemics and mathematical modeling studies had shown that once a new transmissible influenza virus would start to circulate locally among humans it could be contained if immediate stringent control measures were taken, but that once it started spreading, it would be only a matter of time before it would be a global problem. So unless a pandemic started in The Netherlands, whereby an attempt 
at containment could be made [18], control efforts should be focused on mitigating the impact on society at large and the health sector in particular, and on protecting those at risk for severe outcomes. Modeling studies had shown that therapeutic use of antivirals could reduce transmission, while also reducing the risks for those infected $[2,19,20]$, thus the Ministry of Health had purchased 5 million courses of oseltamivir in bulk in 2006, which was all repacked in individual sachets. This should cover the $30 \%$ of the population estimated to develop a symptomatic infection during a pandemic. Furthermore, the ministry started negotiations with vaccine producers to ensure rapid delivery of 34 million doses of the pandemic vaccine once available; two doses for every Dutch citizen, based on the assumption that two doses would be needed to achieve sufficient protection against a novel influenza virus.

\section{Early days}

After the first introduction of the virus in The Netherlands on 27 April 2009 from a child returning from Mexico, the number of imported cases gradually increased, but no sustained widespread community transmission occurred until October 2009 [26]. This early pandemic period was characterized by rapidly evolving insights in risks and management, based on incoming national and international data.

Following the announcement of the WHO of an impending pandemic in late April 2009, the existing protocols for incidental introduction were made operational, with the aim of preventing transmission. Surveillance was strengthened by making confirmed influenza A(H1N1) pdm infection notifiable. Diagnostic capacity was strengthened by sharing standardized protocols for virological testing [13]. Initially, diagnostics was only performed at RIVM and Erasmus Medical Center; in parallel because the available tests were not yet sufficiently validated for the new virus. During this phase, about ten regional laboratories were validating their assays and when the virus was introduced in The Netherlands and the diagnostic capacity needed to be extended, these ten laboratories were

Bundesgesundheitsbl 2013 · 56:67-75 DOI 10.1007/s00103-012-1582-4

(c) Springer-Verlag Berlin Heidelberg 2012

M.A.B. van der Sande · A. Jacobi · A. Meijer · J. Wallinga · W. van der Hoek · M. van der Lubben The 2009 influenza A (H1N1) pandemic. Management and vaccination strategies in The Netherlands

\section{Abstract}

Prior to 2009, The Netherlands had prepared itself extensively for a potential pandemic. Multidisciplinary guidelines had been drafted to control transmission and limit adverse outcomes for both a phase of early incidental introduction and for a phase with widespread transmission. The Ministry of Health had ensured a supply and distribution schedule for antivirals and negotiated a contract for vaccine purchases. During the pandemic, existing surveillance was expanded, the established infectious disease response structure was activated, and the previously prepared protocols for communication, diagnostics, use of antivirals, and vaccination implementation were operationalized and implemented.

When the pandemic turned out to be less severe than many had anticipated, risk communication and rapid modification of guidelines and communication became a major challenge. Antivirals and pandemic vaccines were reserved for those at high risk for severe outcomes only. Overall, the impact of the pandemic was comparable to the impact of an average seasonal influenza epidemic, but with a shift in (severe) outcomes from the very young and elderly toward young adults. Established prepared protocols enabled timely coordinated responses. In preparing for the worst, sufficient attention must be given to preparing for a mild scenario as well.

Keywords

2009 influenza pandemic · Vaccination - The Netherlands · Preparation · Control

\section{Die Influenza-A-(H1N1-)Pandemie 2009. Bewältigung und Impfstrategien in den Niederlanden}

\section{Zusammenfassung}

Vor 2009 hatten sich die Niederlande ausführlich auf eine potenzielle Pandemie vorbereitet. Zur Kontrolle der Übertragung und Begrenzung ungünstiger Verläufe waren sowohl für eine Frühphase der anfänglichen Einschleppung als auch für eine Phase weitverbreiteter Übertragung multidisziplinäre Leitlinien erstellt worden. Das Ministerium hatte einen Versorgungs- und Verteilungsplan für antivirale Substanzen erstellt und über einen Vertrag zum Kauf von Impfstoffen verhandelt. Während der Pandemie wurde die bestehende Überwachung ausgeweitet, das etablierte Reaktionsverfahren für Infektionskrankheiten aktiviert und die zuvor erstellten Protokolle für Kommunikation, Diagnostik, Einsatz antiviraler Substanzen und Impfdurchführung wurden ein- und umgesetzt.

Als sich herausstellte, dass die Pandemie nicht so schwer wie befürchtet war, wurden die Risikokommunikation sowie die schnelle
Modifizierung der Leitlinien und ihre Kommunikation zur wesentlichen Herausforderung. Antivirale Substanzen und Pandemieimpfstoffe waren nur für Personen reserviert, bei denen ein hohes Risiko für eine schwere Erkrankung bestand. Insgesamt waren die Auswirkungen der Pandemie vergleichbar mit denen einer durchschnittlichen saisonalen Influenzaepidemie, allerdings mit einer Verlagerung von (schweren) Erkrankungen von den ganz Jungen und Älteren zu jungen Erwachsenen. Etablierte vorbereitete Protokolle ermöglichten zeitlich koordinierte Reaktionen. Bei der Vorbereitung auf das Schlimmste muss auch der Einstellung auf ein weniger dramatisches Szenario ausreichende Aufmerksamkeit geschenkt werden.

\section{Schlüsselwörter}

Influenzapandemie 2009 · Impfung . Niederlande $\cdot$ Vorbereitung $\cdot$ Kontrolle able to take over the diagnostics from the RIVM and Erasmus Medical Center.

A response team was formed at the RIVM/CIb that met daily (later twice weekly) to discuss the latest developments. Conclusions of the response team were discussed with the ministry on a daily basis through videoconference. Several OMT meetings were convened, where advice for the Ministry of Health was formulated on appropriate control interventions, such as social distancing, closing 


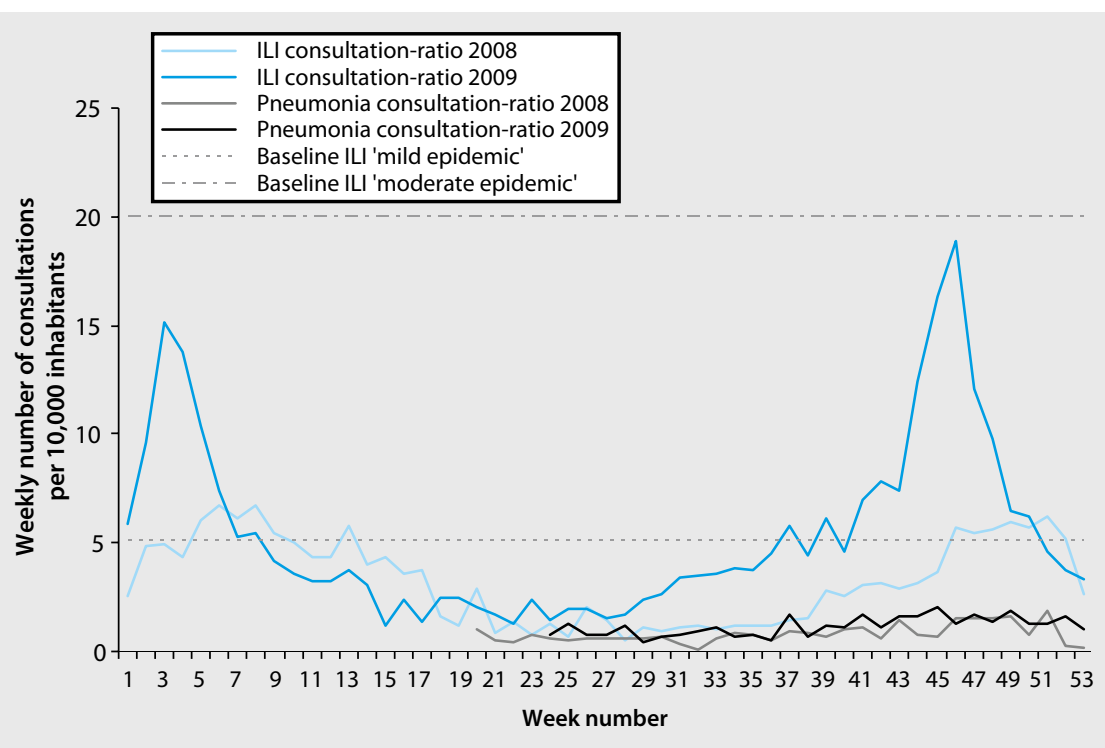

Fig. $1 \Delta$ Weekly incidence of influenza-like illness (ILI) in 2008 and 2009. ILI incidence in GP practices per 10,000 people in 2008 (light blue line) and 2009 (dark blue line). Weekly incidence of pneumonia per 10,000 people in GP practices (gray line, 2008; black line, 2009)

borders, use of masks, use of antivirals. Information for the public and for professionals was made available via the RIVM website, updated on a weekly basis. The RIVM/CIb provided information to public health professionals directly by a bidirectional communication tool distributed by e-mail (Inf@ct). The preparedness and response unit of the RIVM/CIb routinely has a $24 / 7$ availability rooster to assist public health professionals, which proved to be very valuable during these early days as well.

In June, the ministry decided to order 34 million doses of pandemic vaccine.

\section{Challenges}

In spite of all preparations, and the rapid designation of pandemic influenza as a notifiable disease, considerable effort was needed to have an operational case register, combining in a systematic way all relevant data for individual case management, control, surveillance, and outbreak investigations [21]. In particular, the different needs of those providing data inputs, and general privacy concerns, needed to be dealt with during a hectic period. Also, the amount of resources needed to identify and follow up all (suspected) patients and their contacts threatened to stretch the capacity and support of the PHSs to the limit. Therefore, the workload for the public health sector in the early days of the pandemic was very high, raising concerns about the ability to maintain such intensive efforts over a prolonged period of time, particularly because it was unknown at that moment if the worst was still to come.

Furthermore, the lack of a surveillance of severe outcomes was felt as a major weakness, and therefore over the summer, a weekly surveillance system among pediatric ICUs was set up as the most feasible method to bridge this gap during an ongoing outbreak. Collaboration with Statistics Netherlands ensured that weekly data on all-cause mortality by age, sex, and region were sent to the RIVM/CIb to allow real-time monitoring of mortality trends.

\section{Management}

Early control efforts included a social distancing approach toward the first cases and their contacts, as well as providing leaflets to travelers arriving by plane from endemic areas asking them to report fever if it developed [22]. Modeling had shown that closure of borders was unlikely to be an efficient way to delay introduction [23]. The PHSs visited each of these cases; nasopharyngeal and throat swabs were taken. Confirmed cases and contacts were offered antivirals (oseltamivir) and patients were requested to stay at home for 10 days from the start of onset. Detailed household studies provided important data on transmission parameters such as $\mathrm{R}_{0}$ and generation intervals, which were used to update existing transmission models already developed to guide and support control [24]. Cases and their contacts were furthermore requested to participate in the prepared influenza research protocol. With the increase in individual cases and with the accumulating data that the pandemic virus generally caused mild disease, comparable to seasonal influenza, support for this delay policy through social distancing and reduction of transmission declined. The epidemiology data of the early phase were published both nationally and internationally $([25,26]$, - Fig. 1).

\section{Modifications}

On 22 June, the OMT advised that there was no longer a rationale to continue this intensive containment approach, in view of ongoing introductions and subsequent transmission, the mild character of most infections so far, the excessive burden this was placing on the PHSs, and the limited adherence. On 15 August 2009, the official notification requirements were modified, in that only hospitalizations and deaths with laboratory-confirmed pandemic influenza needed to be notified.

The OMT had requested a group of clinical experts to prepare guidelines on the clinical indications for use of antivirals; these guidelines in essence restricted use of antivirals to those with increased risk for adverse outcomes once infected, in line with the recognized risk groups for vaccination [27]. This meant that existing guidelines had to be adapted. Finally, the RIVM/CIb set up a working group with intensive care physicians to estimate available capacity and prepare contingency plans if needed.

\section{Epidemic phase}

By the time schools reopened after the summer holidays in The Netherlands, between mid-August and early September, the evidence for a modest clinical impact was increasing. Transmission and clinical impact remained at low levels until over 


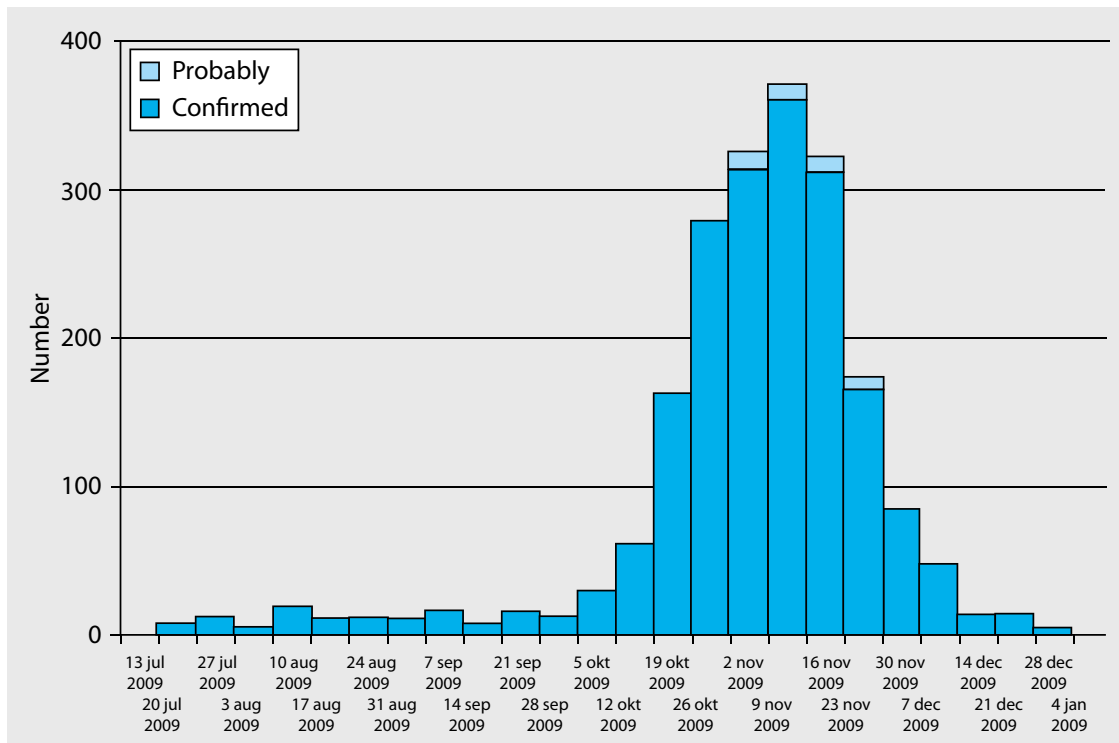

a

Date of hospitalisation

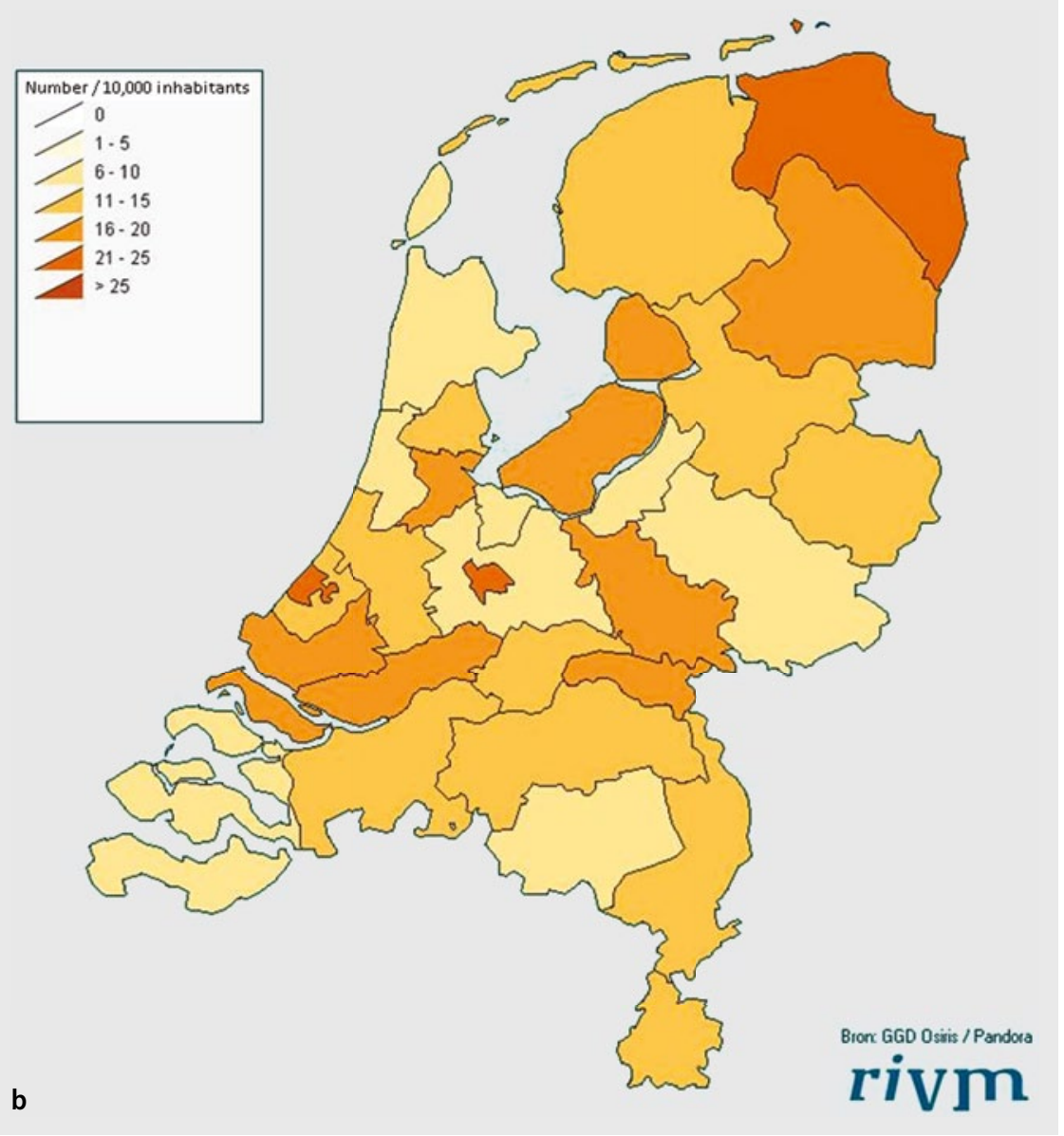

Fig. $2 \Delta$ Final epidemic overview of notified hospitalizations due to confirmed influenza $A(H 1 N 1)$ $\mathrm{pdm}$ in The Netherlands in time (a numbers by week) and place (b incidence by province). Epidemic overview. a Number of notified influenza $A(H 1 N 1) p d m$ hospitalization per week: $x$-axis, weeks of the year; $y$-axis, number of notified influenza $A(\mathrm{H} 1 \mathrm{~N} 1)$ pdm hospitalization. b 2009 incidence of influenza $A(H 1 N 1) p d m$ hospitalizations by province: ranging from 1-5/100,000 (lightest color code) to $>25 / 100,000$ (darkest color). Light blue: laboratory confirmation missing. Orivm a month after reopening of the schools; there had been no spring or summer wave in The Netherlands. Due to the cessation of the notification, and the inability to track the epidemic progression in the regular GP surveillance owing to its low intensity, the number of reported hospitalizations, ICU admissions, and deaths was the most informative real-time data source, recognizing that this created a bias toward monitoring severe outcomes. To adjust for delay in notifications, modeling experience was used to enable nowcasting of the epidemic [28].

Temporary school closure as a method to delay and reduce the peak incidence had been a control option considered in the preparation for an epidemic phase $[29,30]$. The general mild character of the pandemic versus the potentially considerable societal and economic fall-out of temporary school closures made this strategy no longer proportional. Although some individual schools did close (in part or in full) when faced with a large degree of flu absenteeism, overall this remained a rare event.

Nevertheless, anxiety among healthcare professionals in particular remained high. In spite of the lifting of the policy to delay epidemic introduction, PHSs remained extremely busy, and it was therefore decided to postpone the introduction of the annual national HPV campaign for 12-year-old girls, as this would have stretched the PHSs even further and might also jeopardize uptake in the pandemic vaccination campaigns. Furthermore, pediatricians were worried of being overwhelmed with ill babies and young children in the hospitals. Among the general public, there was on the one hand a feeling that the threat was overestimated, but on the other hand there was also still fear of an unpredictable severe course, in particular when the death of previously healthy children in the beginning of the epidemic was picked up by the media and widely publicized. Trust in government communication was in general high, but declined during the course of the pandemic [31].

The epidemic actually took off in the first week of October (week 41), when the ILI epidemic threshold in the sentinel surveillance was surpassed $(>5.1$ ILI 

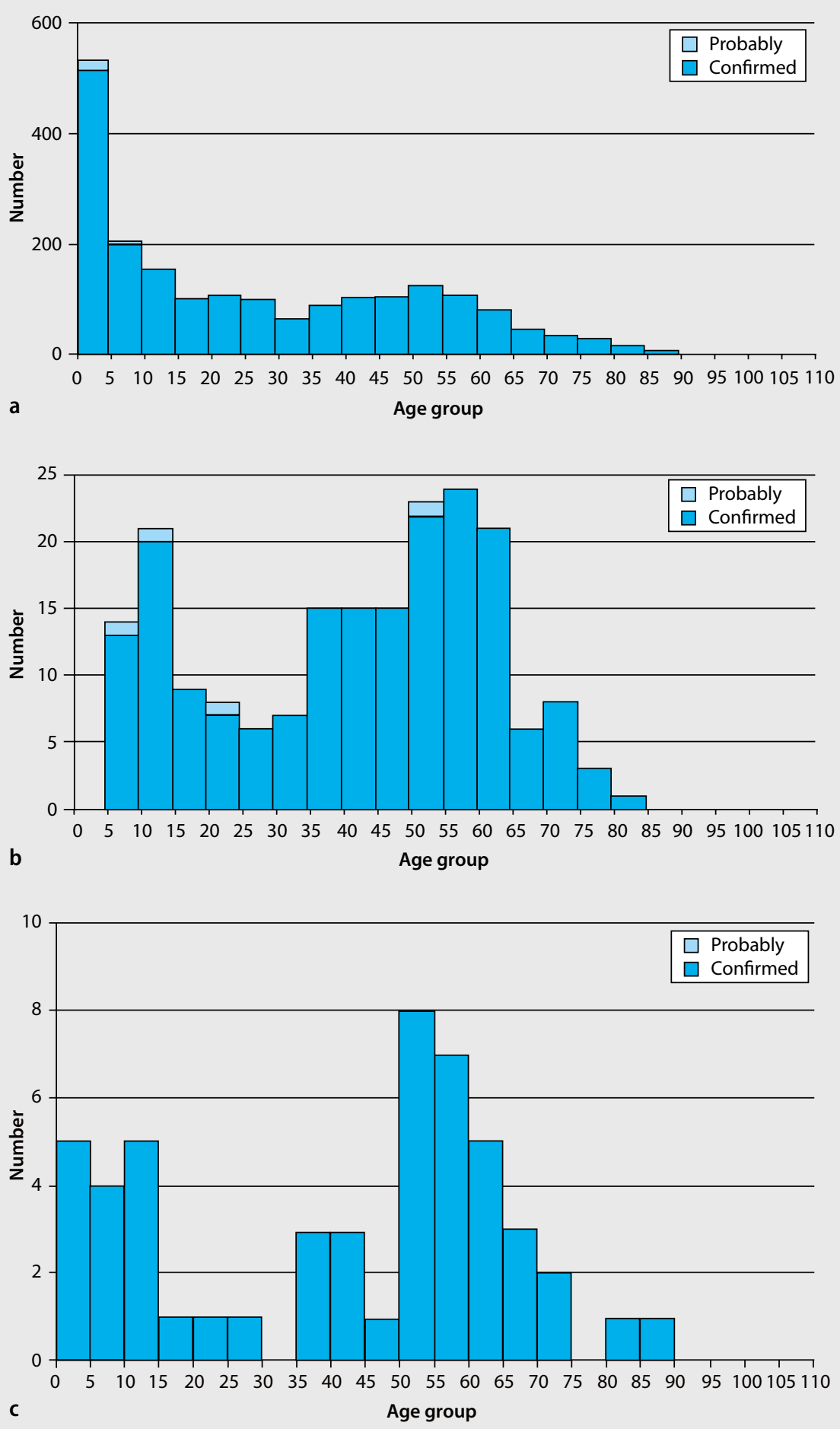

Fig. 3 A Epidemic impact differs by age: a hospitalizations; $\mathbf{b}$ ICU admissions; and $\mathbf{c}$ deaths (all by age). Changing severity with age. a Number of notified influenza A(H1N1)pdm hospitalizations in 2009 by age group: $x$-axis, age categories; $y$-axis, number of notified influenza $A(H 1 N 1) p d m$ hospitalization. b Number of notified intensive care (IC) influenza $A(H 1 N 1)$ pdm admissions in 2009 by age group: $x$ axis, age categories; $y$-axis, number of notified influenza $\mathrm{A}(\mathrm{H} 1 \mathrm{~N} 1) \mathrm{pdm}$ IC admissions. c Number of notified influenza $A(H 1 N 1) p d m$ deaths in 2009 by age group: $x$-axis, age categories; $y$-axis, number of notified influenza $A(\mathrm{H} 1 \mathrm{~N} 1)$ pdm deaths. Light blue: laboratory confirmation missing

cases/10,000 population). Sachets with antivirals from the national stockpile had been sent to all pharmacies (mak-
Weekly surveillance updates were provided on the RIVM website starting in June (• Fig. 1), accompanied by weekly wellattended press conferences beginning in August whereby the director of the CIb would give a brief update and answer press questions. Specific themes were highlighted during each week, e.g., vaccination, side effects, etc..

The pandemic season lasted for 10 weeks and included the autumn midterm school breaks: week 43 for the northern and central part of The Netherlands and week 44 for the southern part. The epidemic peaked in week 45 ; in week 1 of 2010, the last regular pandemic surveillance update was published. An overall overview based on notified patients was published in Eurosurveillance [32]. A pre- and postpandemic population-based serologic survey showed that the overall attack rate was low (7.6\%) in the general population, but high (35\%) in 5-19-year-olds. Hospitalization and mortality rates per infection increased significantly with age [17]. Overall mortality was comparable to seasonal epidemics, but a clear shift in mortality toward younger age groups was found $[33,34]$. Use of antivirals among nonhospitalized patients with an indication for use remained low (Hooijveld et al., manuscript submitted). Viral resistance monitoring continued, and in spite of the detection of several resistant viruses, no sustained transmission occurred [12]. Notification of hospitalized and deceased patients continued until after the 2010-2011 season [33].

Overall, the high infection attack rate in children and very low attack rate in older adults, together with the low severity of illness per infection in children but substantial severity in older adults, produced an epidemic with a low overall impact and a comparable burden of disease to seasonal epidemics ([35, 36, 37], • Fig. 2, 3).

\section{Vaccination}

In The Netherlands, childhood vaccinations included in the Dutch National Immunization Programe are delivered by PHSs free of charge to the recipients. Children or their parents are invited once a vaccination is due. This results in a high overall uptake. Seasonal influenza vacci- 
Tab. 1 Pandemic vaccination in The Netherlands: uptake

Estimated uptake by target group [38, 40, 41, 43]

\begin{tabular}{llll}
\hline & Pandemic 1st dose (\%) & Pandemic 2nd dose (\%) & Seasonal (\%) \\
\hline Age indication $(\geq 60)$ & 77 & 69 & $76^{\text {a }}$ \\
\hline Medical indication $(<60$ years) & 63 & 54 & 59 \\
\hline HCWs & 50 & 43 & 20 \\
\hline Children $<5$ years & 74 & 62 & n/a \\
\hline Pregnant women & 63 & 58 & \\
\hline a 82\% for those aged 65 and above & & & \\
\hline
\end{tabular}

Tab. 2 Pandemic vaccination in The Netherlands: effectiveness

\begin{tabular}{|c|c|}
\hline Outcome & Vaccine effectiveness (95\% Cl) \\
\hline ILI crude & $48 \%(-29-+79)$ \\
\hline ILI age-adjusted & $35 \%(-76-+76)$ \\
\hline Hospitalization & $19 \%(-28-+49)$ \\
\hline Hospitalization medical indications & $49 \%(+16-+69)$ \\
\hline
\end{tabular}

nation for high-risk groups, including the elderly, is delivered by GPs and by nursing homes, also free of charge for the eligible groups.

Prior to the pandemic, the Dutch Health Council had discussed which groups should be vaccinated first in case availability of vaccines would be lower than needed. Priority should be given to those at highest risk for severe outcomes, followed by healthcare workers. When over the summer of 2009 more and more data became available that in general the infection did not lead to severe outcome, the Health Council advised in August that for pandemic vaccination the same risk groups as for seasonal vaccination should be targeted (i.e., people with underlying conditions, people 60 years of age and above, and healthcare professionals) with the addition of pregnant women, as these were the groups considered at highest risk of severe adverse outcomes. Thereby, vaccination was primarily intended to reduce severe morbidity and mortality, not to interrupt transmission. Although data on the effectiveness of a single dose of vaccination in healthy adults became available, the Health Council advised to maintain a two-dose schedule, as they considered there were insufficient data available to assess effectiveness for the risk groups targeted in The Netherlands (not healthy adults), and no shortage was foreseen.
Pandemic vaccination for these risk groups was implemented by the GPs, as this is a successful and tested strategy for seasonal vaccination of risk groups. GPs receive a financial compensation for each vaccinated person, and influenza vaccination is free of charge for those with a recommendation to receive the vaccine [as is the case for all (targeted) vaccinations provided by the government]. Overall, seasonal influenza vaccination uptake for medical risk groups below the age of 65 years is around $70 \%$ and for the elderly over $80 \%$ [6]. Monitoring of uptake in these groups was as always done via GP registers. Vaccination of healthcare professionals is organized by the health sector. Seasonal uptake in this group is hard to assess, but in general estimated to be around $20 \%$ for nursing home staff [38] and over 50\% for GPs [39]. Vaccination uptake in pregnant women, a new target group, was hardest to assess, as no routine structure was available. Therefore, this was assessed via retrospective questionnaires among pregnant women [40].

Making use of these existing structures, pandemic vaccination was rolled out as soon as vaccines were available. Seasonal vaccination had gone ahead as scheduled for healthcare staff, the elderly, and medical risk groups in October, followed by the start of pandemic vaccination early November with Pandemrix ${ }^{\otimes}$ for these same groups, plus pregnant wom- en and for healthcare professionals, with a second dose offered after 2 weeks.

In early November 2009, concern about potential overburdening of the health services by sick young children, in particular children too young to be treated with antivirals, led to an additional recommendation to vaccinate all children between the ages of 6 months and 5 years, as well as the caretakers of babies between 0 and 6 months. Vaccinations of children in The Netherlands are routinely provided through the PHS. Apart from the routine infant and child vaccinations, protocols existed for mass vaccination campaigns, and had been used and tested for a meningitis $B$ vaccination campaign in 2003 [41]. Mass vaccination of children with Focetria ${ }^{\circ}$ was started in late November, with the second dose offered 2 weeks later in the beginning of December.

This approach meant that the implementation of a pandemic vaccination strategy could build on established and tested practices, including trust between the people invited and the people inviting. Thus, in spite of ongoing discussions in the media regarding the need for pandemic vaccination ("mild epidemic"), concerns about limited data on long-term safety of adjuvanted novel vaccines, and extensive media attention for potential conflict of interests between pharmacy and government advisors, the overall uptake of pandemic vaccination was good, comparable to uptake of seasonal vaccination for those eligible ([40, 42, 43], • Tab. 1, 2). Comparable to the situation with seasonal vaccination, uptake among healthcare workers was the main challenge. Employers are responsible to order and distribute the vaccines. For institutions with no prior experience in annual seasonal vaccination campaigns, this was a major challenge. A helpdesk for the ordering and logistic issues was established at the RIVM, as the RIVM was responsible for the logistics of the vaccination distributions.

Uptake of the second dose was between 80 and $90 \%$ of the first dose in the different target groups (• Tab. 1, 2). Overall, an estimated one third of the population (5 million people) was vaccinated.

In view of the use of a novel vaccine, intensified monitoring for side effects was conducted by the RIVM/CIb togeth- 
er with Netherlands Pharmocovigilance Centre, but no unexpected unusual adverse events were reported.

Vaccine effectiveness was estimated using the same test-negative method as used to estimate seasonal vaccine effectiveness. In spite of an excellent match with the circulating strains, overall vaccine effectiveness was moderate $([44,45]$, • Tab. 1, 2).

\section{Evaluation and lessons learned}

Extensive evaluations have been conducted by many involved parties in The Netherlands, aided by a detailed chronological overview of events [46]. The longterm multidisciplinary preparation for a pandemic, as well as the strong structure established for control and communication, proved crucial for a coordinated response. Guidelines, surveillance, mathematical modeling could all build on each other's contributions and strengths. This is despite the fact that a (severe) pandemic caused by an avian influenza virus originating from Asia was anticipated, rather than a (relatively mild) swine-origin virus from Mexico.

Nevertheless, how to communicate that preparing for the worst does not imply that the worst will happen remained a challenge. Sufficient attention in preparing for mild scenarios too might save resources, facilitate risk communication, optimize the effectiveness of control, and increase trust in authorities.

Also, even with many guidelines in place, a great amount of effort was required to assess the continuous flow of more and more new data both in the scientific and in the lay press about the impact of the pandemic on individuals and on the population level, and about the effectiveness of interventions. Such data had to be evaluated for their scientific merit, assessed against available local data as well as their relevance to the specific Dutch situation. Estimations of impact based on modeled assumptions had to be updated rapidly as new data became available. On the one hand, maximum flexibility was needed to modify guidelines and procedures where indicated [47], on the other hand, continuity in control and communication was essential as well.
Furthermore, in spite of numerous exercises and a stand-by multisectoral database, a significant amount of effort was needed to collect and analyze all incoming data from clinicians, laboratories, and public health officials in a standardized and structured way, which put stress on (internal) communications and reduced the potential for rapid outbreak investigations [21].

Surveillance benefited from well-established routines and longitudinal data. Setting up SARI surveillance during the pandemic was only feasible because of the strong commitment of a well-identified group of pediatric ICUs; work is still ongoing to try and make this a part of routine surveillance.

\section{Conclusion}

In a crisis such as a pandemic, good generic preparation is essential, as this enables building on established practices and trust. However, the continuous media attention and shifting public opinions, along with rapidly accumulating scientific data, necessitates maximum flexibility so as to maintain effective and credible management.

\section{Corresponding address}

\section{M.A.B. van der Sande}

RIVM - Centre Infectious Disease Control, National Institute for Public Health and the Environment, Bilthoven

3720 BA Bilthoven

The Netherlands

marianne.van.der.sande@rivm.nl

Acknowledgments. The authors would like to acknowledge all the clinicians, public health officials, laboratory staff, other professionals, patients, and contacts involved; many other RIVM workers involved in pandemic control; and the Dutch Government, ECDC, and WHO.

Conflict of interest. On behalf of all authors, the corresponding author states that there are no conflicts of interest.

\section{References}

1. Genugten ML van, Heijnen ML, Jager JC (2003) Pandemic Influenza and healthcare demand in the Netherlands: scenario analysis. Emerg Infect Dis 9:531-538

2. Hagenaars TJ, van Genugten MLL, Wallinga J (2004) Pandemic influenza and health care demand: dynamic modelling. Int Congr Ser 1263:235-238

3. Koopmans M, Wilbrink B, Conyn M et al (2004) Transmission of H7N7 avian influenza A virus to human beings during a large outbreak in commercial poultry farms in the Netherlands. Lancet 363:587-593

4. Asten $L$ van, Lubben $M$ van der, Wijngaard $C$ van den et al (2009) Strengthening the diagnostic capacity to detect Bio Safety Level 3 organisms in unusual respiratory viral outbreaks. J Clin Virol 45:185-190. (Erratum in: J Clin Virol 2010; 47:204)

5. Opstelten W, Steenbergen JE van, Essen GA van, Sande MA van der (2009) Threat of an influenza pandemic: family physicians in the front line. BMC Fam Pract 10:11

6. Donker GA, Gravestein J (2007) The best time for flu vaccination. Huisarts en Wetenschap 50:41. (Dutch.)

7. Dijkstra F, Donker GA, Wilbrink B et al (2009) Long time trends in influenza-like illness and associated determinants in The Netherlands. Epidemiol Infect 137:473-479

8. Enserink R, Meijer A, Dijkstra F et al (2011) Absence of influenza $A(H 1 N 1)$ during seasonal and pandemic seasons in nursing home network. J Am Geriatr Soc 59:2301-2305

9. Jonges $M$, Lubben IM van der, Dijkstra $F$ et al (2009) Dynamics of antiviral-resistant influenza viruses in the Netherlands, 2005-2008. Antiviral Res 83:290-297

10. Vries E van der, Jonges $M$, Herfst $S$ et al (2010) Evaluation of a rapid molecular algorithm for detection of pandemic influenza A (H1N1) 2009 virus and screening for a key oseltamivir resistance (H275Y) substitution in neuraminidase. J Clin Virol 47:34-37

11. Dijkstra F, Jonges $M$, Beek R van et al (2011) Influenza $A(H 1 N 1)$ Oseltamivir resistant viruses in the Netherlands during the winter 2007/2008. Open Virol J 5:154-162

12. Meijer A, Jonges $M$, Abbink F et al (2011) Oseltamivir-resistant pandemic A(H1N1) 2009 influenza viruses detected through enhanced surveillance in the Netherlands, 2009-2010. Antiviral Res 92:8189

13. Meijer A, Beerens A, Claas E et al (2009) Preparing the outbreak assistance laboratory network in the Netherlands for the detection of the influenza virus $A(H 1 N 1)$ variant. J Clin Virol 45:179-184

14. Friesema IHF, Meijer A, Gageldonk-Lafeber AF van et al (2012) Coures of pandemic influenza A(H1N1) 2009 virus infection in Dutch patients. Influenza Other Respi Viruses 6:e16-e20

15. Koopmans M, Bruin E de, Godeke GJ et al (2011) Profiling of humoral immune responses to influenza viruses by using protein microarray. Clin Microbiol Infect doi:10.1111/j.1469-0691.2011.03701.x [Epub ahead of print]

16. Vinck L, Isken L, Hooiveld M et al (2011) Impact of the 2009 influenza $A(\mathrm{H} 1 \mathrm{~N} 1)$ pandemic on public health workers in the Netherlands. Euro Surveill 16:pii19793 
17. Steens A, Waaijenborg S, Teunis PFM et al (2011) Age-dependent patterns of infection and severity explain the low impact of 2009 influenza $\mathrm{A}(\mathrm{H} 1 \mathrm{~N} 1)$ : evidence from serial population-based serological surveys. Am J Epidemiol 174:1307-1315

18. Ferguson NM, Cummings DA, Cauchemez $S$ et al (2005) Strategies for containing an emerging influenza pandemic in Southeast Asia. Nature 437:209214

19. Ferguson NM, Cummings DA, Fraser C et al (2006) Strategies for mitigating an influenza pandemic. Nature 442:448-452

20. Lugnér AK, Mylius SD, Wallinga J (2010) Dynamic versus static models in cost-effectiveness analyses of anti-viral drug therapy to mitigate an influenza pandemic. Health Econ 19:518-531

21. Whelan J, Greenland K, Rondy M et al (2012) Case registry systems for pandemic influenza $\mathrm{A}(\mathrm{H} 1 \mathrm{~N} 1)$ in Europe: are there lessons for the future? Euro Surveill 17: pii 20167

22. Swaan CM, Appels R, Kretzschmar MEE, Steenbergen JE van (2011) Timeliness of contact tracing among flight passengers for influenza $A / H 1 N 1$ 2009. BMC Infect Dis 11:355

23. Scalia Tomba G, Wallinga JA (2008) Simple explanation for the low impact of border control as a countermeasure to the spread of an infectious disease. Math Biosci 214:70-72

24. Boven $M$ van, Donker $T$, Lubben $M$ van der et al (2010) Transmission of novel influenza $A(H 1 N 1)$ in households with post-exposure antiviral prophylaxis. PLoS One 5:e11442

25. Vriend HJ, Hahne SJM, Donker T et al (2009) The new influenza $A(H 1 N 1)$-epidemic in the Netherlands. Ned Tijdschr Geneeskd 153:A969. (Dutch.)

26. Hahné S, Donker T, Meijer A et al (2009) Epidemiology and control of influenza $A(\mathrm{H} 1 \mathrm{~N} 1) \mathrm{v}$ in the Netherlands: the first 115 cases. Euro Surveill 14:pii:19267

27. Dissel JT van, Coutinho RA, Sande MAB van der (2009) Neuraminidase inhibitors for increased risk of influenza complications: balanced and supported advice. Ned Tijdschr Geneeskd 153:B486. (Dutch.)

28. Donker T, van Boven $M$, van Ballegooijen WM et al (2011) Nowcasting pandemic influenza (H1N1)2009 hospitalisations in the Netherlands. Eur J Epidemiol 26:195-201

29. Cauchemez S, Ferguson NM, Wachtel C et al (2009) Closure of schools during an influenza pandemic. Lancet Infect Dis 9:473-481

30. Wallinga J, Boven M van, Lipsitch M (2010) Optimizing infectious disease interventions during an emerging epidemic. Proc Natl Acad Sci U S A 107:923-928

31. Weerd $W$ van der, Timmermans DR, Beaujean DJ et al (2011) Monitoring the level of government trust, risk perception and intention of the general public to adopt protective measures during the influenza A (H1N1) pandemic in The Netherlands. BMC Public Health 11:575

32. Klooster T van't, Wielders CC, Donker T et al (2010) Surveillance of Hospitalisations for 2009 Pandemic Influenza $A(H 1 N 1)$ in the Netherlands, 5 June-31 December 2009. Euro Surveill 15:pii:19461

33. Gageldonk-Lafeber AB van, Riesmeijer RM, Friesema IHM et al (2011) Case-based reported mortality associated with laboratory-confirmed influenza $A(H 1 N 1) 2009$ virus infection in the Netherlands: the 2009-2010 pandemic season versus the 20102011 influenza season. BMC Public Health 11:758
34. Wijngaard CC van den, Asten L van, Koopmans M et al (2012) Comparing pandemic to seasonal influenza mortality: Moderate impact overall but high mortality in young children. PloS One 7:e31197

35. Gageldonk AB van, Hooiveld M, Meijer A et al (2011) The relative clinical impact of 2009 pandemic influenza $A(\mathrm{H} 1 \mathrm{~N} 1)$ in the community compared to seasonal influenza in the Netherlands was most marked among 5-14 year olds. Influenza Other Respi Viruses 5:e513-e520

36. De Jong JC, Rimmelzwan GF, Donker GA et al (2001) The Mexican flu pandemic of 2009: an overview with a focus on the Netherlands. Ned Tijdsch Med Microbiol 19:6-12. (Dutch.)

37. Wielders CC, Lier EA van, Klooster TM van't et al (2012) The burden of 2009 pandemic influenza $A(H 1 N 1)$ in the Netherlands. Eur J Public Health 22:150-157

38. Looijmans-van den Akker I, Delden JJ van, Hak E (2007) Uptake of influenza vaccination in Dutch nursing home personnel following national recommendations. J Am Geriatr Soc 55:1486-1487

39. Opstelten W, Essen GA van, Heijnen ML et al (2010) High vaccination rates for seasonal and pandemic (A/H1N1) influenza among healthcare workers in Dutch general practice. Vaccine 28:6164-6168

40. Van Lier A, Steens A, Ferreira JA et al (2012) Acceptance of vaccination during pregnancy: experience with 2009 influenza A (H1N1) in the Netherlands. Vaccine 30:2892-2899

41. Greeff SC de, Melker HE de, Spanjaard L et al (2003) The first effect of the national vaccination campaign against meningococcal-C disease: a rapid and sharp decrease in the number of patients. Ned Tijdschr Geneeskd 147:1132-1135. (Dutch.)

42. Hanquet $\mathrm{G}$, Damme P van, Brasseur D et al (2010) Lessons learnt from pandemic $A(H 1 N 1) 2009$ influenza vaccination. Highlights of a European workshop in Brussels (22 March 2010). Vaccine 29:370377

43. Tacken M, Mulder J, Visscher S et al (2010) Monitoring vaccination uptake Dutch National Program Influenza Prevention 2009. LINH, IQ Healthcare, Nijmegen

44. Steens A, Hoek W van der, Dijkstra F, Sande M van der (2011) Influenza vaccine effectiveness, 2010/11. Euro Surveill 16:pii19843

45. Steens A, Wijnans EG, Dieleman JP et al (2011) Effectiveness of a MF-59 ${ }^{\mathrm{TM}}$-adjuvanted pandemic influenza vaccine to prevent $2009 \mathrm{~A} / \mathrm{H} 1 \mathrm{~N} 1$ influenza-related hospitalisation; a matched case-control study. BMC Infect Dis 11:196

46. Stein ML, Vliet JA van, Timen A (2011) Chronological overview of the 2009/2010 H1N1 influenza pandemic and the response of the Centre for Infectious Disease Control RIVM. Bilthoven; RIVM Report 215011006/2011

47. Weeramanthri TS, Robertson AG, Dowse GK et al (2010) Response to pandemic (H1N1)2009 influenza in Australia-lessons from a State health department perspective. Aust Health Rev 34:477486

\section{Neues Computermodell simuliert Ausbreitung von Seuchen}

Epidemien könnten sich zukünftig leichter eindämmen lassen. Mit Hilfe eines neuen Computermodells könnten jene Personen identifiziert werden, welche eine Infektion am stärksten verbreiten. Dies ist vor allem dann wichtig, wenn Impfstoff knapp ist. Wer eine Infektion am aktivsten überträgt, ist oft schwierig vorherzusagen. Eine neue Computersimulation zeigt nun, dass nicht immer eine starke Vernetzung entscheidend ist. Auch Personen, die wenig Kontakte haben, können zur Verbreitung einer Infektion beitragen. Das Verfahren berechnet, wie viele Personen sich durch einen erstinfizierten Patienten 0 nach einer gewissen Zeit angesteckt haben. Dabei werden Wege über bereits infizierte Personen außer Acht gelassen, da diese bereits immun sind. Je größer die Zahl der möglichen Wege, desto größer ist die Wahrscheinlichkeit, dass ein weiterer Patient $X$ infiziert wird. Die Zeit in der sich eine Epidemie ausbreitet entspricht dabei den Personen, die zwischen Patient 0 und Patienten $x$ liegen. Dies wird für alle Personen des Netzwerkes berechnet und liefert so erstmals absolute Zahlen zum Verlauf von Epidemien.

Als Modellsystem wählten die Forscher das virtuelle Netzwerk einer Forschergemeinschaft. Die Daten lieferten Archive wissenschaftlicher Publikationen. Gemeinsame Autorenschaft steht dabei stellvertretend für direkten persönlichen Kontakt. Die neue Computersimulation ist nicht nur 2000 Mal schneller und genauer als bisherige Methoden. Sie liefert auch erstmals wichtige Informationen über die Bedeutung von Netzwerk-Strukturen, z.B. kleinere Cluster wie Dörfer.

Literatur:

Bauer F und Lizier J (2012) Identifying influential spreaders and efficiently estimating infection numbers in epidemic models: A walk counting approach. EPL [Published ahead of print] doi: $10.1209 / 0295-5075 / 99 / 68007$ 